\title{
Summary of $\mathrm{NACl}$ Statement: Interim Recommendations on the Use of Pneumococcal Vaccines in Immunocompetent Adults 65 Years of Age and Older
}

\author{
Quach $\mathrm{C}^{1}$, Baclic $\mathrm{O}^{2}$ on behalf of the National Advisory Committee on Immunization (NACl)*
}

\begin{abstract}
Background: Since 2015, pneumococcal 13-valent conjugate vaccine (PNEU-C-13) has been authorized for the prevention of invasive pneumococcal disease (IPD) and pneumococcal community-acquired pneumonia (CAP) in adults. Adults with immunocompromising conditions are still recommended to receive PNEU-C-13 followed by the pneumococcal 23-valent polysaccharide vaccine (PNEU-P-23). National Advisory Committee on Immunization (NACI) guidance has been requested on the use of PNEU-C-13 vaccine in immunocompetent adults 65 years of age and older.
\end{abstract}

Objectives: To make recommendations, at the individual level, for the use of PNEU-C-13 in immunocompetent adults 65 years of age and over.

Methods: The NACI Pneumococcal Working Group (PWG) reviewed key questions and performed an evidence review and synthesis. In consideration of the burden of illness to be prevented, the target population, safety, immunogenicity, efficacy and effectiveness of the vaccine, the PWG proposed recommendations for vaccine use to $\mathrm{NACl}$. All evidence was rated and reported in evidence tables. $\mathrm{NACl}$ approved specific evidence-based recommendations and elucidated the rationale and relevant considerations in the statement update.

Results: $\mathrm{NACl}$ identified and reviewed evidence from one randomized controlled trial investigating the efficacy of PNEU-C-13 to prevent IPD and CAP in adults who were immunocompetent at enrollment and three clinical trials assessing the immunogenicity in immunocompetent and immunocompromised adults.

Conclusions: Based on reviewed evidence, $\mathrm{NACl}$ issued new recommendations for the use of pneumococcal vaccines in immunocompetent adults 65 years of age and older.

\section{Affiliations}

${ }^{1} \mathrm{NACl}$ Pneumococcal Working

Group Chair, Montréal, QC

${ }^{2}$ Centre for Immunization and Respiratory Infectious Diseases, Public Health Agency of Canada, Ottawa, ON

*Correspondence: naci-ccni@ phac-aspc.gc.ca

Suggested citation: Quach C, Baclic O on behalf of the National Advisory Committee on Immunization (NACl). Summary of NACl Statement: Interim Recommendations on the Use of Pneumococcal Vaccines in Immunocompetent Adults 65 Years of Age and Older. Can Comm Dis Rep 2016;42(12):260-2.

https://doi.org/10.14745/ccdr.v42i12a05

\section{Introduction}

Infections caused by Streptococcus pneumoniae are a major cause of morbidity and mortality worldwide. In Canada, the burden of disease is highest in young children and older adults (1).

Since January 2012, pneumococcal 13-valent conjugate vaccine (PNEU-C-13) has been authorized for use in adults 50 years of age and older for the prevention of invasive pneumococcal disease (IPD) caused by S. pneumoniae serotypes included in the vaccine (2). Since 2013, the National Advisory Committee on Immunization (NACl) has recommended the use of PNEU-C-13 vaccine, followed by the pneumococcal 23-valent polysaccharide vaccine (PNEU-P-23), in adults with immunocompromising conditions (3). Following the approval of an expanded adult indication of PNEU-C-13 vaccine for the prevention of pneumococcal community-acquired pneumonia (CAP) in 2015 (4), $\mathrm{NACl}$ was requested to provide additional guidance on its use in immunocompetent adults 65 years of age and older.

\section{Methods}

The NACI Pneumococcal Working Group (PWG) reviewed key questions and performed an evidence review and synthesis. In consideration of the burden of illness to be prevented, the target population, safety, immunogenicity, efficacy and effectiveness of the vaccine, the PWG proposed recommendations for vaccine use to $\mathrm{NACl}$. All evidence was rated and reported in evidence tables. $\mathrm{NACl}$ approved specific evidence-based 
recommendations and elucidated the rationale and relevant considerations in the statement update.

\section{Results}

PWG and NACl reviewed evidence from four trials for the efficacy of PNEU-C-13 vaccine. No studies on the effectiveness of PNEU-C-13 vaccine were identified through the literature search. Efficacy data of PNEU-C-13 to prevent IPD and CAP in adults who were immunocompetent at enrollment were reported in one trial (5) and three trials provided data on vaccine immunogenicity in immunocompetent and immunocompromised adults (6-8).

\section{Conclusion}

Based on reviewed evidence, $\mathrm{NACl}$ issued two recommendations for the use of pneumococcal vaccines in immunocompetent adults 65 years of age and older.

\section{Recommendation 1:}

$\mathrm{NACl}$ concludes that there is good evidence, on an individual basis, to recommend in immunocompetent adults aged 65 years and older not previously immunized against pneumococcal disease, the use of PNEU-C-13 vaccine followed by PNEU-P-23, for the prevention of CAP and IPD caused by the 13 pneumococcal serotypes included in the conjugate vaccine. (NACl Recommendation Grade A).

In immunocompetent adults aged 65 years and older, PNEU-C-13 vaccine has been shown to be safe and moderately efficacious against CAP and IPD caused by the 13 serotypes included in the vaccine. There are no effectiveness studies on PNEU-C-13 in adult populations. In clinical trials, local adverse events such as injection site pain and systemic adverse events, such as fatigue and newly occurring generalized pain were common but overall mild.

If immunization with PNEU-C-13 vaccine is being considered, pneumococcal vaccine-naïve individuals should first receive PNEU-C-13 vaccine, followed by PNEU-P-23 vaccine at least 8 weeks later. The purpose of administering PNEU-P-23 to an individual who has already received PNEU-C-13 is to expand the breadth of serotypes against which an individual is protected. For immunization of individuals who have previously received PNEU-P-23 vaccine, $\mathrm{NACl}$ recommends administration of PNEU-C-13 at least one year after any previous dose of PNEU-P-23 vaccine, due to the theoretical potential for decrease in antibody titers following immunization with PNEU-P-23 vaccine.

\section{Recommendation 2:}

$\mathrm{NACl}$ concludes that, based on circulating serotypes, there is fair evidence to recommend the use of PNEU-P-23 vaccine in routine immunization programs for adults aged 65 years and older. (NACl Recommendation Grade B)

Because the burden of pneumococcal disease caused by serotypes included in the PNEU-P-23 vaccine, but not contained in the PNEU-C-13 vaccine remains significant, $\mathrm{NACl}$ continues to recommend the administration of PNEU-P-23 for all adults 65 years of age and older who have not received either vaccine previously. PNEU-C-13 vaccine effectiveness is dependent on the circulation of vaccine specific serotypes. Comparative immunogenicity studies between PNEU-C-13 and PNEU-P-23 indicate that Geometric Mean Titres (GMTs) are higher in elderly subjects vaccinated with PNEU-C-13 for eight serotypes that are common to both vaccines, but the clinical and population-level implications associated with this improved immunogenicity remains unclear. No additional booster dose of PNEU-P-23 vaccine is currently recommended for those over the age of 65 years who do not have other underlying medical conditions that would put them at higher risk for IPD or severe CAP.

A complete review of evidence and full $\mathrm{NACl}$ recommendations on the use of pneumococcal vaccine are published in the $\mathrm{NACl}$ statement update (9) and the pneumococcal vaccine chapter of the Canadian Immunization Guide (10). Recommendations that consider other public health aspects of pneumococcal immunization will be addressed in a forthcoming $\mathrm{NACl}$ statement.

\section{Acknowledgements}

NACI Members: Gemmill I (Chair), Quach C (Vice-Chair), Dayneka N, Deeks S, Henry B, Marchant-Short S, Salvadori M, Sicard N, Vaudry W, Vinh D, Warrington R

Liaison Representatives: Blake J (Society of Obstetricians and Gynaecologists of Canada), Brophy J (Canadian Association for Immunization Research and Evaluation), Cohn A (Centers for Disease Control and Prevention, United States), Emili J (College of Family Physicians of Canada), Lavoie M (Council of Chief Medical Officers of Health), Mah C (Canadian Public Health Association), Moore D (Canadian Paediatric Society), Pham-Huy A (Association of Medical Microbiology and Infectious Disease Canada), Sartison E (Canadian Immunization Committee)

Ex-Officio Representatives: Barnes K (National Defence and the Canadian Armed Forces), Charos G (Centre for Immunization and Respiratory Infectious Diseases [CIRID], Public Health Agency of Canada [PHAC]), Coleman G (Biologics and Genetic Therapies Directorate, Health Canada [HC]), Gallivan J (Marketed Health Products Directorate [MHPD], HC), Pennock J (CIRID, PHAC), Wong $T$ (First Nations and Inuit Health Branch [FNIHB], HC) 
This statement was prepared by the Pneumococcal Working Group: Quach C (Chair), DeWals P, Fisman D, Johnstone J, Kellner J, McNeil S, Rechner S, Tyrrell G.

$\mathrm{NACl}$ acknowledges and appreciates the contribution of Oliver Baclic, Christina Jensen, Lindsey Sherrard and Nicholas Winters to the statement.

\section{Funding}

The work of $\mathrm{NACl}$ is supported by the Public Health Agency of Canada.

\section{Conflict of interest}

None.

\section{References}

1. Public Health Agency of Canada (PHAC). Invasive pneumococca disease [Internet]. Ottawa ON: PHAC; 2016. [updated 2016 Mar 10; cited 2016 Aug 11]. Available from: http://www.phac-aspc. gc.ca/im/vpd-mev/pneumococcal-pneumococcie/professionalsprofessionnels-eng.php.

2. Pfizer Canada. Health Canada approves extended use of Prevnar ${ }^{\circledR} 13$ in adults 50 years and older. Canada Newswire. 2015 Feb 15. Available from: http://www.newswire.ca/newsreleases/health-canada-approves-extended-use-of-prevnar-13in-adults-50-years-and-older-509639921.html.

3. Advisory Committee Statement (ACS) National Advisory Committee on Immunization (NACl). Statement on the use of conjugate pneumococcal vaccine - 13 valent in adults (Pneu-C-13). Ottawa ON: PHAC; 2013. [updated 2013 Oct 30; cited 2016 Aug 11]. Can Comm Dis Rep [Internet]. 2013;39(ACS5):3-50 Available from: http://www.phac-aspc. gc.ca/publicat/ccdr-rmtc/13vol39/acs-dcc-5/index-eng.php.
4. Pfizer Canada. Prevnar® 13 now approved in Canada for the prevention of vaccine-type pneumococcal pneumonia in adults 18 years of age and older. Canada Newswire. 2015 Aug 5. 2015. Available from: http://www.newswire.ca/news-releases/prevnar13-now-approved-in-canada-for-the-prevention-of-vaccinetype-pneumococcal-pneumonia-in-adults-18-years-of-age-andolder-520737471.html.

5. Bonten MJM, Huijts SM, Bolkenbaas M, et al. Polysaccharide conjugate vaccine against pneumococcal pneumonia in adults. N Engl J Med 2015;372:1114-1125.

6. Tinoco JC, Juergens C, Ruiz Palacios GM, et al. Open-label trial of immunogenicity and safety of a 13-valent pneumococcal conjugate vaccine in adults $\geq 50$ years of age in Mexico. Clin Vaccine Immunol 2015;22(2):185-92.

7. Jackson LA, Gurtman A, van Cleeff M, et al. Immunogenicity and safety of a 13-valent pneumococcal conjugate vaccine compared to a 23-valent pneumococcal polysaccharide vaccine in pneumococcal vaccine-naive adults. Vaccine 2013;31(35):3577-84.

8. Glesby MJ, Watson W, Brinson C, et al. Immunogenicity and safety of 13-valent pneumococcal conjugate vaccine in HIVinfected adults previously vaccinated $\mathrm{w} 1$ ith pneumococcal polysaccharide vaccine. J Infect Dis 2015;212(1):18-27.

9. Advisory Committee Statement (ACS) National Advisory Committee on Immunization (NACl). Update on the use of 13-valent pneumococcal conjugate vaccine (PNEU-C-13) in addition to 23-valent pneumococcal polysaccharide vaccine (PNEU-P-23) in immunocompetent adults 65 years of age and older - Interim recommendation [Internet]. Ottawa: PHAC; 2016 [cited 2016 Oct 17]. Available from: http://www. healthycanadians.gc.ca/publications/healthy-living-vie-saine/ update-pneu-c-13-and-pneu-p-23-mise-a-jour-2016/indexeng.php.

10. National Advisory Committee on Immunization (NACl). Canadian immunization guide, Part 4, Active vaccines, pneumococcal vaccine [Internet]. Ottawa ON: PHAC; 2015. [updated 2015 Mar 24; cited 2016 Aug 11]. Available from: http://www.phac-aspc.gc.ca/publicat/cig-gci/p04-pneu-eng.php.

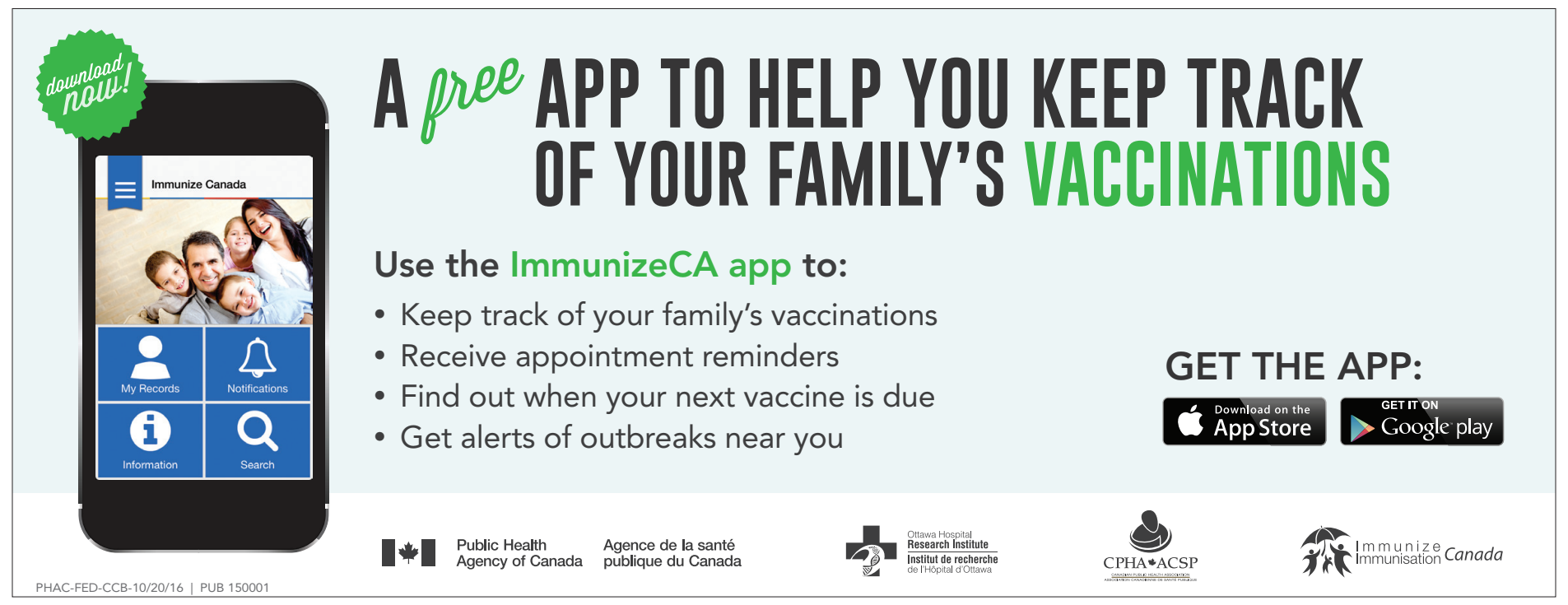

